\title{
The Effect of Non-cavity-Distorting Myomas on the Outcomes of Stimulated Intrauterine Insemination in Unexplained Infertility
}

(1) Özge AKDENIZ̈a,
(1) Nadiye KÖROĞLUa,
(1) Gonca YETKIN YILDIRIMa,
(1) Berna ASLAN ÇETINª,
İbrahim POLATa
'Department of Obstetrics and Gynecology,
Health Sciences University
Kanuni Sultan Süleyman Training and
Research Hospital,
İstanbul, TURKEY
Received: 26.10 .2018
Received in revised form: 28.11 .2018
Accepted: 29.11 .2018
Available online: 15.01 .2019
Correspondence:
Nadiye KÖROĞLU
Health Sciences University
Kanuni Sultan Suleyman Training and
Research Hospital,
Department of Obstetrics and Gynecology,
İstanbul, TURKEY
nadiye_dugan@ hotmail.com

\begin{abstract}
Objective: To investigate the relationship between reproductive outcomes and noncavity-distorting uterine myomas in women with unexplained infertility and undergoing ovulation induction and intrauterine insemination (OI-IUI). Material and Methods: Women between 18-40 years of age with regular ovulatory cycles and bilateral tubal patency as detected on hysterosalpingography (HSG) and with spouses having total progressive motile sperm (TPMSS) counts $>5$ million on spermiogram analysis, were included in this study. The number of women with noncavity-distorting myomas, as detected using ultrasonography, were recorded. The frequencies of pregnancies after OI-IUI, ectopic pregnancies, abortions, clinical pregnancies, and live births were compared between women with non-cavity-distorting myomas and those without myomas. Results: A total of 857 cycles of OI-IUI were administered to 436 patients, resulting in 110 pregnancies. Non-cavity-distorting myomas were recorded in 27 subjects. Using multivariate logistic regression analysis, the presence of non-cavity-distorting myoma significantly affected pregnancy $(p<0.05)$. Conception $(p=0.008)$, clinical pregnancy $(p=0.034)$, and live birth rates $(p=0.037)$ were significantly higher in patients without fibroids than those with fibroids. Conclusion: Conception, clinical pregnancy, and live birth rates were significantly higher in patients without uterine fibroids than those with fibroids. These findings suggest that myomas might have negative effects on fertility outcomes.
\end{abstract}

Keywords: Myoma uteri; infertility; intrauterine insemination

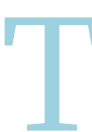

he definition of unexplained infertility includes all sperm or oocyte dysfunctions, or developmental disorders of fertilization, implantation, or embryogenesis, that cannot be diagnosed from standard fertility tests. Fifteen percent of all couples are diagnosed with unexplained infertility. ${ }^{1}$ Myomas may be detected in $20-40 \%$ of all women in the reproductive age and $5-10 \%$ of infertile women., ${ }^{2,3}$ However, in $1-2 \%$ of the women with infertility, myomas are the only abnormal finding. ${ }^{4}$ Abnormal bleeding, pain, and compression in adjacent organs constitute the majority of myoma-related complaints, while the effects of myomas on fertility are more difficult to identify. Most of the evidence regarding the impact of myomas on fertility arises from the studies comparing the prevalence of myomas in fertile and infertile women, and those comparing the fertility outcomes of women with unexplained infertility before and after myomectomy. 4,5

There is a clear consensus that submucous myomas have significant negative impacts on clinical pregnancy and live birth, whereas sub-serosal fibroids do not unfavorably affect pregnancy outcomes..$^{5-8}$ However, it is 
more challenging to conclude that intramural myomas have adverse effects on fertility and pregnancy outcomes. While some studies reported negative impacts of myomas, several others could not. ${ }^{9-18}$ Myoma and unexplained infertility are thought to have similar pathologies, with the pathogenesis of both involving inflammatory pathways, hormonal imbalances, and genetic alterations.

The present study proposes to investigate the effect of non-cavity distorting uterine fibroids on pregnancy outcomes in patients with unexplained infertility and undergoing ovulation induction (OI) with gonadotrophins and intrauterine insemination (IUI).

\section{MATERIAL AND METHODS}

The study was conducted as a retrospective cohort trial at the infertility clinic in Kanuni Sultan Süleyman Training and Research Hospital (KSSTRH). The study was approved by the local ethics committee (KSSTRH ethics committee, 2/2018) was done in accordance with the Declaration of Helsinki.

The medical records of patients who had undergone OI with gonadotropins and IUI between January 2010 and December 2017 following diagnosis of unexplained infertility at our infertility clinic were retrospectively analyzed.

Women between 18-40 years of age, with a regular ovulatory cycle, a normal endometrial cavity with bilateral tubal patency as detected using hysterosalpingography (HSG), and having male partners with total progressive motile sperm (TPMSS) counts $>5$ million/mL were included in the study.

Female patients with thyroid hormone disorders, hyperprolactinemia and other endocrine disorders, anovulatory cycles, tubal pathology as detected using HSG, endometriosis, intrauterine adhesions, polyps, or Mullerian duct anomalies (uterine septum, T-shaped uterus, etc.), and male partners with TPMSS counts $<5$ million/mL were excluded from the study. The patients with submucosal myomas, myomas impairing the uterine cavity, or having a history of myomectomy were also excluded from the study.

The baseline demographic and reproductive characteristics of couples were recorded.

The ultrasound images of patients were reviewed from their files. Patients with non-cavitydistorting uterine myomas were identified. The locations of the myomas, types according to FIGO classification, sizes, and numbers were recorded.

Pregnancy was considered as a positive reaction in the $\beta$-HCG test performed 14 days after IUI. Clinical pregnancy was defined as the presence of fetal heart beat using ultrasonography. Live birth was defined as the delivery of a viable infant.

\section{STATISTICAL ANALYSIS}

The statistical program SPSS (Statistical Package for Social Sciences) version 22.0 was used for statistical analysis of the data. Descriptive statistical tools (frequency, percentage, mean, standard deviation) were used. The Kolmogorov-Smirnov test was used to assess the distribution of data. Comparisons of the variables with normal distributions were done using the chi-square test. In univariate analysis, Pearson's chi-square test and Fisher's exact test were used to evaluate pregnancy-related risk factors. The values of $\mathrm{p}<0.05$ were considered statistically significant.

\section{RESULTS}

A total of 436 patients were included in the study. A total of 857 IUI procedures were recorded. Noncavity-distorting myomas were detected in $6.2 \%$ (n $=27$ ) of the 436 patients included in this study. The average diameter of myomas in these 27 patients was found to be $30.6 \mathrm{~mm}$. Five patients had two myomas, one patient had multiple myomas, and the remaining patients had only one myoma. According to the FIGO classification, the types of myomas ranged from type $4(6 / 27)$ to type $5(21 / 27)$. There was no difference between the groups in terms of the age, BMI, baseline TPMSS, and infertility type (Table 1).

On the third day of the menstrual cycle, levels of FSH and E2, antral follicle counts, and size of the 


\begin{tabular}{|c|c|c|c|}
\hline & Fibroid $(+)(n=27)$ & Fibroid (-) (n=409) & $p$ value \\
\hline Female age (years) & $32.1 \pm 3.8$ & $29.0 \pm 4.4$ & $<0.001$ \\
\hline Male age (years) & $32.5 \pm 2.9$ & $31.9 \pm 4.7$ & 0.466 \\
\hline BMl (kg/m2) & $23.8 \pm 3.0$ & $24.4 \pm 3.3$ & 0.403 \\
\hline Duration of infertility (years) & $4.8 \pm 3.3$ & $4.0 \pm 2.6$ & 0.150 \\
\hline \multicolumn{4}{|l|}{ Infertility type (\%) } \\
\hline Primary & 20 & 327 & \multirow{2}{*}{0.680} \\
\hline Secondary & 7 & 92 & \\
\hline $\mathrm{FSH}$ & $7.3 \pm 2.2$ & $6.9 \pm 1.9$ & 0.392 \\
\hline E2 & $50.8 \pm 20.8$ & $53.4 \pm 34.5$ & 0.706 \\
\hline AFC & $9.1 \pm 3.4$ & $9.7 \pm 4.0$ & 0.477 \\
\hline DF diameter (mm) & $17.2 \pm 1.4$ & $17.4 \pm 1.7$ & 0.637 \\
\hline Baseline TPMSC-(million) & $29,7 \pm 19,7$ & $18,5 \pm 25,02$ & 0.751 \\
\hline Postwash TPMSC (million) & $17,1 \pm 15,4$ & $22,1 \pm 23,01$ & 0.276 \\
\hline Starting gonadotropin dose & $57.2 \pm 17.8$ & $53.2 \pm 17.4$ & 0.274 \\
\hline Total cycle day & $7.9 \pm 2.1$ & $8.7 \pm 3.0$ & 0.191 \\
\hline
\end{tabular}

FSH: Follicle stimulating hormone; E2: Estradiol; AFC: Antral Follicul count; DF: Dominant follicle; BMI: Body mass index; TPMSC: Total Progressive Motile Sperm count. $p<0.05$ is considered statistically significant. Data are expressed as mean $( \pm S D)$ or proportions $(\%)$.

largest dominant follicle were similar between groups (Table 1). There was no difference between the groups in terms of the initial gonadotropin dose and the period of gonadotropin administration.

Rates of pregnancy following OI-IUI were observed to be $3.7 \%$ and $26.6 \%$ in subjects with or without uterine fibroids, respectively $(\mathrm{p}=0.008)$. The rates of clinical pregnancy were $3.7 \%$ and $20 \%$ in subjects with uterine fibroids and without fibroids, respectively $(\mathrm{p}=0.034)$. The rates of live births in subjects with or without uterine fibroids were $0 \%$ and $13.9 \%$, respectively $(\mathrm{p}=0.037$ ) (Table 2 ).

In multivariate logistic regression analysis, the effect of uterine myomas on pregnancy was statistically significant $(\mathrm{p}<0.05)$ (Table 3$)$.

\section{DISCUSSION}

There is no clear consensus about the effects of non-cavity-distorting uterine myoma on conception and gonadotropin-IUI cycles. In this study, we observed that the rates of conception, clinical pregnancy, and live birth were significantly lower in the subjects with unexplained infertility and noncavity-distorting uterine myoma, compared to the controls without myomas.

Approximately $5 \%$ to $10 \%$ of patients presenting with infertility have one or more myomas. ${ }^{4}$ However, when all other causes of infertility are excluded, myoma is observed in only $1 \%$ to $2 \%$ of the infertile women. ${ }^{4,19}$ Our findings of the presence of myoma in $6.2 \%$ of the cases with unex-

\begin{tabular}{|c|c|c|c|}
\hline & Fibroid (+) ( $n=27)$ & Fibroid (-) (n=409) & $p$ value \\
\hline Conception & $1 / 27(3.7)$ & $109 / 409(26.6)$ & 0.008 \\
\hline Clinical pregnancy & $1 / 27(3.7)$ & $82 / 409(20)$ & 0.034 \\
\hline Abortus & $1 / 1(100)$ & $50 / 109(45.8)$ & 0.413 \\
\hline Ectopic pregnancy & $0 / 1(0)$ & 2/109 (1.8) & 0.880 \\
\hline Live birth & $0 / 27(0)$ & $57 / 409$ (13.9) & 0.037 \\
\hline
\end{tabular}

Data are expressed as number of subjects/total number (proportions).

$p<0.05$ is considered statistically significant. 


\begin{tabular}{|cccc|}
\hline \multicolumn{4}{|c|}{ TABLE 3: The effect of myomas on pregnancy } \\
in multivariant analysis. \\
\hline \multirow{3}{*}{ RR $(95 \%$ Cl) } & p value \\
\hline Fibroid & $\begin{array}{l}\text { Absence } \\
\text { Present }\end{array}$ & $0.107(0.014-0.800)$ & 0.029 \\
\hline
\end{tabular}

RR: Risk ratio. $p<0.05$ is considered statistically significant.

plained infertility were compatible with those reported in the literature. ${ }^{4}$

The effects of myomas on fertility are best assessed in studies comparing outcomes of in vitro fertilization (IVF) in women with and without fibroids since the effects of IVF and other confounding factors affecting fertility can be controlled. Numerous studies have examined the effects of varying size and location of myomas on fertility. There is a general consensus that submucous myomas and myomas disrupting the contours of the endometrial cavity have significant negative effects on clinical pregnancy and live-birth rates, while sub-serous myomas do not have any negative effects on IVF outcomes. ${ }^{9} 10,20$ However, the findings of studies investigating the effects of noncavity-distorting uterine myomas on IVF outcomes are inconsistent. Hart and colleagues reported a significant reduction in clinical pregnancy and live birth rates in women with intramural myomas measuring less than $5 \mathrm{~cm}$ (median diameter $2.3 \mathrm{~cm}$ ) compared to women without intramural myomas. ${ }^{12}$ In contrast, Check et al. indicated no difference in terms of clinical pregnancy and live birth rates in cases with non-cavity-distorting myomas measuring $\leq 5 \mathrm{~cm} \cdot{ }^{17}$ In a meta-analysis involving 19 studies, Sunkara et al. found a significant decrease in clinical pregnancy (RR: 0.85) and live birth rates (RR: $0.6)$ in cases with non-cavity-distorting myomas ranging from $0.7 \mathrm{~cm}$ to $5 \mathrm{~cm}$ in diameter. The authors concluded that non-cavity-distorting fibroids decreased the expected live birth rates and adversely affected pregnancy outcomes. ${ }^{21}$ In the present study, both clinical pregnancy and live birth rates were significantly lower in cases with myoma than those without myoma. Thus, myomas had a negative impact on OI-IUI cycles. Although the mean age was significantly higher in the myoma group in this study, the effect of age on pregnancy outcomes was not significant, as the decline in agerelated fertility is especially noticeable around the age of 35 .

Apart from the presence of myomas, other factors such as the size and number of myomas are also strongly associated with infertility. Somigliana et al. reported that patients with asymptomatic intramural or sub-serous myomas measuring $<5 \mathrm{~cm}$ had similar live birth rates as the control group and did not affect IVF outcomes. ${ }^{22}$ In contrast, Yan et al. observed lower rates of live birth in patients with intramural myomas with a maximum diameter of $2.85 \mathrm{~cm}$, compared to the control group. ${ }^{23}$ Therefore, the size of the myoma is one of the most important variables that may affect pregnancy rates in women with non-cavity-distorting uterine myoma. The median diameter of the myomas observed in this study was $30.6 \mathrm{~mm}$ and our results suggest that myomas might have negative effects on fertility outcomes.

As shown in previous studies, the most prominent effects of myomas on fertility are associated with implantation..$^{21,24} \mathrm{We}$ suggest that the decrease in pregnancy rates in case of myomas that do not disturb the uterine cavity is caused by the interrupted implantation due to altered intrauterine blood flow. Myomas have also been associated with abnormal expression of endometrial growth factors and cytokines involving cell proliferation, differentiation, and angiogenesis; thus, lower pregnancy rates in the current study may have been associated with these factors. ${ }^{24}$

Although accumulating evidence continues to suggest that intramural myomas adversely affect fertility outcomes, it is unclear whether myomectomy will improve outcomes. Casini et al. reported that women undergoing myomectomy had similar clinical pregnancy rates as women that did not undergo surgical intervention. ${ }^{25}$ The authors of another review emphasized that removal of type 3 to type 6 myomas (according to the FIGO leiomyoma classification) measuring less than $4 \mathrm{~cm}$ in diameter can be considered only after unsuccessful IVF attempts. ${ }^{26}$ Therefore, there are no data to support the routine myomectomy in women with small intramural non-cavity-distorting uterine myomas. ${ }^{27}$ 
The major limitations of this study were the bias due to its retrospective nature, and a relatively small sample size of the myoma group.

\section{CONCLUSION}

In conclusion, small intramural myomas may adversely affect fertility outcomes in unexplained infertility; however, when considering myomectomy, other factors such as age, ovarian reserve, and unsuccessful infertility treatments should also be evaluated in addition to the location and size of the myoma.

\section{Source of Finance}

During this study, no financial or spiritual support was received neither from any pharmaceutical company that has a direct connection with the research subject, nor from a company that provides or produces medical instruments and materials which may negatively affect the evaluation process of this study.

\section{Conflict of Interest}

No conflicts of interest between the authors and / or family members of the scientific and medical committee members or members of the potential conflicts of interest, counseling, expertise, working conditions, share holding and similar situations in any firm.

\section{Authorship Contributions}

Idea/Concept: Nadide Köroğlu; Design: Nadide Köroğlu, Gonca Yıldırım; Control/Supervision: İbrahim Polat; Data Collection and/or Processing: Özge Akdeniz, Berna Aslan Çetin; Analysis and/or Interpretation: Berna Aslan Çetin; Literature Review: Gonca Yıldırım; Writing the Article: Özge Akdeniz, Nadide Köroğlu; Critical Review: Gonca Yıldırım, İbrahim Polat; References and Fundings: Berna Aslan Çetin.
1. Ray A, Shah A, Gudi A, Homburg R. Unexplained infertility: an update and review of practice. Reprod Biomed Online 2012; 24(6):591-602.

2. DeWaay DJ, Syrop $\mathrm{CH}$, Nygaard IE, Davis WA, Van Voorhis BJ. Natural history of uterine polyps and leiomyomata. Obstet Gynecol 2002;100(1):3-7.

3. Verkauf BS. Myomectomy for fertility enhancement and preservation. Fertil Steril 1992;58(1):1-15.

4. Donnez J, Jadoul P. What are the implications of myomas on fertility? A need for a debate? Hum Reprod 2002;17(6):1424-30.

5. Pritts EA. Fibroids and infertility: a systematic review of the evidence. Obstet Gynecol Surv 2001;56(8):483-91.

6. Myomas and reproductive function. Fertil Steril 2008;90(5 Suppl):S125-30.

7. Ezzati M, Norian JM, Segars JH. Management of uterine fibroids in the patient pursuing assisted reproductive technologies. Womens Health (Lond) 2009;5(4):41321.

8. Pritts EA, Parker WH, Olive DL. Fibroids and infertility: an updated systematic review of the evidence. Fertil Steril 2009;91(4):121523.

9. Eldar-Geva $T$, Meagher $S$, Healy DL, MacLachlan V, Breheny S, Wood C. Effect of intramural, subserosal, and submucosal uterine fibroids on the outcome of assisted

\section{REFERENCES}

reproductive technology treatment. Fertil Steril 1998;70(4):687-91.

10. Stovall DW, Parrish SB, Van Voorhis BJ, Hahn SJ, Sparks AE, Syrop CH. Uterine leiomyomas reduce the efficacy of assisted reproduction cycles: results of a matched follow-up study. Hum Reprod 1998;13(1):1927.

11. Healy DL. Impact of uterine fibroids on ART outcome. Environ Health Perspect 2000;108 Suppl 5:845-7.

12. Hart $R$, Khalaf $Y$, Yeong $C T$, Seed $P$, Taylor A, Braude P. A prospective controlled study of the effect of intramural uterine fibroids on the outcome of assisted conception. Hum Reprod 2001;16(11):2411-7.

13. Khalaf $Y$, Ross $C$, El-Toukhy $T$, Hart R, Seed $P$, Braude $P$. The effect of small intramural uterine fibroids on the cumulative outcome of assisted conception. Hum Reprod 2006;21(10):2640-4.

14. Klatsky PC, Tran ND, Caughey AB, Fujimoto VY. Fibroids and reproductive outcomes: a systematic literature review from conception to delivery. Am J Obstet Gynecol 2008; 198(4):357-66.

15. Dietterich C, Check JH, Choe JK, Nazari A, Fox $F$. The presence of small uterine fibroids not distorting the endometrial cavity does not adversely affect conception outcome following embryo transfer in older recipients. Clin Exp Obstet Gynecol 2000;27(3-4):16870.
16. Surrey ES, Lietz AK, Schoolcraft WB. Impact of intramural leiomyomata in patients with a normal endometrial cavity on in vitro fertilization-embryo transfer cycle outcome. Fertil Steril 2001;75(2):405-10.

17. Check JH, Choe JK, Lee G, Dietterich C. The effect on IVF outcome of small intramural fibroids not compressing the uterine cavity as determined by a prospective matched control study. Hum Reprod 2002;17(5): 1244-8.

18. Oliveira FG, Abdelmassin VG, Diamond MP, Dozortsev D, Melo NR, Abdelmassih R. Impact of subserosal and intramural uterine fibroids that do not distort the endometrial cavity on the outcome of in vitro fertilizationintracytoplasmic sperm injection. Fertil Steril 2004;81(3):582-7.

19. Cook H, Ezzati M, Segars JH, McCarthy K. The impact of uterine leiomyomas on reproductive outcomes. Minerva Ginecol 2010; 62(3):225-36.

20. Farhi J, Ashkenazi J, Feldberg D, Dicker D, Orvieto R, Ben Rafael Z. Effect of uterine leiomyomata on the results of in-vitro fertilization treatment. Hum Reprod 1995;10(10): 2576-8.

21. Sunkara SK, Khairy M, El-Toukhy T, Khalaf $Y$, Coomarasamy $A$. The effect of intramural fibroids without uterine cavity involvement on the outcome of IVF treatment: a systematic review and meta-analysis. Hum Reprod 2010;25(2):418-29. 
22. Somigliana $E$, De Benedictis $S$, Vercellini $P$, Nicolosi AE, Benaglia L, Scarduelli C, et al. Fibroids not encroaching the endometrial cavity and IVF success rate: a prospective study. Hum Reprod 2011;26(4):834-9.

23. Yan L, Yu Q, Zhang YN, Guo Z, Li Z, Niu J, et al. Effect of type 3 intramural fibroids on in vitro fertilization-intracytoplasmic sperm injection outcomes: a retrospective cohort study. Fertil Steril 2018;109(5):817-22.e2.

24. Wyndham N, Marin Figueira PG, Patrizio P. A persistent misperception: assisted reproductive technology can reverse the "aged biological clock". Fertil Steril 2012;97(5): 1044-7.

25. Casini ML, Rossi F, Agostini R, Unfer V. Effects of the position of fibroids on fertility. Gynecol Endocrinol 2006;22(2):106-9.
26. Galliano D, Bellver J, Diaz-García C, Simón C, Pellicer A. ART and uterine pathology: how relevant is the maternal side for implantation? Hum Reprod Update 2015;21(1):13 38.

27. Surrey ES. Impact of intramural leiomyomata on in-vitro fertilization-embryo transfer cycle outcome. Curr Opin Obstet Gynecol 2003;15(3):239-42. 